\title{
Женский досуг в фабричной повседневности: текстильные предприятия Ярославской губернии во второй половине XIX - начале XX в.
}

\author{
В.М. Марасанова, Ю.А. Кривошеева \\ Ярославский государственный университет им. П.Г. Демидова, \\ Россия, 150003, г. Ярославль, ул. Советская, 14 \\ E-mail:vmm@uniyar.ac.ru, y.krivosheeva@uniyar.ac.ru
}

\begin{abstract}
Аннотация. В статье изучается место досуга в фабричной повседневности текстильщиц Ярославской губернии во второй половине XIX - начале XX века. Исследование проводится с применением гендерного, регионального и микроисторического подходов. Авторами выявляются социально-экономические факторы, оказывавшие влияние на развитие промышленности, процессы труда и отдыха в рабочей среде, приводившие к трансформации идентичности городских и сельских рабочих. В статье освещается многообразие форм досуговых практик, доступных мужчинам и женщинам, а также отмечается тенденция к увеличению доли досуга в повседневной жизни текстильщиц.
\end{abstract}

Ключевые слова: труд, досуг, текстильная промышленность, гендер, работница.

Для цитирования: Марасанова В.М., Кривошеева Ю.А. 2020. Женский досуг в фабричной повседневности: текстильные предприятия Ярославской губернии во второй половине XIX - начале XX в. Via in tempore. История. Политология, 47 (3): 559-567. DOI 10.18413/2687-0967-2020-47-3-559-567.

\section{Women leisure and a factory's everyday life: textile enterprises of the Yaroslavl province in the second half of the XIX $^{\text {th }}-$ early $X^{\text {th }}$ century}

\author{
Victoria M. Marasanova, Ju.A. Krivosheeva \\ P.G. Demidov Yaroslavl State University, \\ 14 Sovetskaya St., Yaroslavl, 150003, Russia \\ E-mail:vmm@uniyar.ac.ru, y.krivosheeva@uniyar.ac.ru
}

\begin{abstract}
The article considers the place of leisure in the factory daily life of the female textile workers of the Yaroslavl province in the second half of the nineteenth - the beginning of the twentieth century. The research has been conducted via gender, regional and microhsitorical approaches. The authors summarize the information on the work schedule at the Russian enterprises in general and at the textile factories of the Yaroslavl province in particular. The article reveals social and economic factors which influenced the development of the textile industry as well as the workers' labour and leisure and led to transformation of urban and rural workers' identity. It also considers the variety of leisure forms available to both men and women, such as background, religious and festive, cultural and educational leisure. The study raises the question of the fullness of the industrial female workers' leisure time and traces the tendency towards the increase of its amount in the women's everyday life. However, during the studied period the leisure time of the female textile workers in the Yaroslavl province was still determined by traditional women responsibilities and gender stereotypes.
\end{abstract}

Keywords: labour, leisure, textile industry, gender, female worker. 
For citation: Marasanova V.M., Krivosheeva Ju.A. 2020. Women leisure and a factory's everyday life: textile enterprises of the Yaroslavl province in the second half of the 19th - early 20th century. Via in tempore. History and political science, 47 (3): 559-567 (in Russian). DOI 10.18413/2687-0967-2020-47-3-559-567.

Понятия труда и досуга неразрывно связаны с повседневной жизнью общества, их изучение позволяет глубже понять социальные процессы, происходившие в стране, отдельных регионах и внутри социальных общностей. Во второй половине XIX - начале $\mathrm{XX}$ в. в российской промышленности меняется соотношение мужского и женского труда. Причиной увеличения количества женщин становится быстрое развитие техники, сокращение рабочего дня, стремление фабрикантов к экономии. Среди прочего, женщины считались более «спокойным и умеренным» элементом по сравнению с рабочимимужчинами. Текстильная индустрия стала первой отраслью промышленности, где отчетливо наметилась тенденция к замещению мужского труда женским [Беликов, 1914, с. 61].

Ярославская губерния как один из типичных текстильных регионов Центральной России может считаться весьма показательной в этом отношении. К примеру, если в 1867 г. численность текстильщиц на сельской Норской мануфактуре составляла $41 \%$, то в 1913 г. превысила 56 \%. На Ярославской Большой мануфактуре (далее - ЯБМ) численность работниц всех возрастов увеличилась с $37 \%$ в 1888 г. до $51 \%$ в 1913 г. [Виноградов и др., 1976, с. 17; Бородкин и др., 2010, с. 73]. Среди прочего, не работавшие на фабриках женщины из семей текстильщиков составляли значительную часть населения «рабочих городков», становясь неотъемлемыми акторами фабричной повседневности [Ярославская Большая мануфактура, 1900, с. 35]. В связи с этим целью исследования представляется изучение места досуга в жизни ярославских текстильщиц и его трансформации под влиянием социально-экономических процессов. Под фабричной повседневностью понимается весь комплекс трудовых и бытовых обязанностей работниц.

Исследование проводилось с применением гендерного, регионального и микроисторического подходов. Гендерный подход позволяет выявить различия повседневности женщин и мужчин, вызванные традиционными стереотипами и моделями поведения. Рассматриваемый период вследствие бурного индустриального роста изменил роль женщин в экономической жизни и обществе в разных странах и на многих континентах. На данную тенденцию обратили внимание исследователи гендерной истории США [Baron A., 1982], Англии [Benenson Н., 2019], Ирландии [James K.J., 2006; Purdue O., 2017], Канады [Вoyer K., 2004], Японии [Hunter J., 1993]. Они справедливо подчеркивали рост масштабов производства и спроса на рабочую силу на рубеже XIX - XX столетий, что приводило к изменениям в структуре профессий по половому признаку и увеличению доли женщин на производстве. Вслед за этим технологии и социальные отношения формировали друг друга как на рабочем месте, так и в быту. В отмеченных выше исследованиях, как правило, отмечалась важность комплексного изучения гендера, труда и опыта трудящихся на основе первичных документов.

В научном фокусе современных российских исследователей находятся брачное поведение, семейный быт, общественная жизнь женщин [Марасанова и др., 2013; Веременко, 2014; Пушкарева, Мицюк, 2016]. Географические рамки исследований, освещающих повседневную жизнь рабочего класса, включают как столичные регионы, так и провинцию [Залунаева, 2005; Бородкин и др., 2010; Посвятенко, 2011].

Источниками исследования стали архивные материалы, в значительной степени впервые вводимые в научный оборот. В Российском государственном историческом архиве (РГИА) анализировались материалы фонда Министерства торговли и промышленности (Ф. 23). В Государственном архиве Ярославской области (ГАЯО) прорабатывались фонды текстильных предприятий - Ярославской Большой мануфактуры (Ф. 674), Норской мануфактуры (Ф. 675), Гаврилов-Ямской мануфактуры А.А. Локалова (Ф. 676), Фабрики льня- 
ных изделий «Наследники П.А. Сакина» (Ф. 652). В филиале ГАЯО в г. Ростове (РсФ ГАЯО) изучался фонд Ростовского уездного комитета попечительства о народной трезвости (Ф. 69), а именно материалы о досуге населения. В фонде Партархива Ярославского обкома КПСС (Ф. 4773) в Центре документации новейшей истории (ЦДНИ) - филиале ГАЯО выявлялись воспоминания текстильщиц.

Хронологические рамки исследования ограничены второй половиной XIX - началом XX в. Нижняя граница определяется началом периода Великих реформ, верхняя граница завершается кануном первой российской революции. Текстильная промышленность Центральной России в этот период переходила на современное импортное оборудование и хлопок в качестве основного сырья. Одновременно происходила трансформация повседневности фабричных рабочих - изменялось соотношение труда и досуга в рамках их обыденной жизни.

Развитие железнодорожного транспорта и промышленности способствовали росту городов и внутренней миграции населения. Малоземелье, неплодородность почв, избыточное количество рабочих рук способствовали развитию крестьянского отхода. Главными направлениями отхода ярославцев оставались Санкт-Петербург и Москва, а Ярославская губерния становилась «центром притяжения» отходников из других губерний. В начале XX столетия в губернии насчитывалось более 30 предприятий ${ }^{76}$, занимавшихся производством полотен, пряжи, канатов, ваты ${ }^{77}$. По количеству рабочих и объемам производимой продукции выделялись ЯБМ, Романовская, Норская, Ростовская и ГавриловЯмская мануфактуры.

Важным достижением стало развитие фабричного законодательства, способствовавшее сокращению рабочего времени и увеличившее долю досуга в фабричной повседневности мужчин и женщин. Ранее текстильщики Центральной России были заняты в производстве в среднем по 13 часов в день [Кирьянов, 1979, с. 55]. Рабочее время не включало перерывы на прием пищи - около 1,5-2 часов. Рабочий день удлинялся за счет необязательных сверхурочных работ, от которых рабочие, как правило, не могли отказаться.

По мере вступления в силу законов 1882-1897 гг. рабочий день малолетних, женщин, а позже и остальных категорий рабочих начал сокращаться. Средняя продолжительность рабочего дня взрослых текстильщиков Ярославской губернии составляла порядка 12 часов $^{78}$, а с 1898 г. сократилась до 11,5 часов. Рабочий день при занятости ночью, а также в субботу и перед праздничными днями сокращался до 10 часов. Ночные работы для женщин и подростков от 15 до 17 лет допускались лишь в случае чрезвычайных обстоятельств и при условии совместной работы с главами их семейств. Время работы малолетних сократилось до 8, а затем - до 6 часов в день. В случае введения на фабриках непрерывной восемнадцатичасовой дневной работы в две смены, продолжительность трудового дня малолетних рабочих увеличивалась до 9 часов ${ }^{79}$. Воскресные работы были запрещены. На ЯБМ под влиянием забастовочного движения 1905 г. было принято решение об уменьшении рабочего времени до 10,5 часов для «денных» рабочих и 9 для сменных.

Крупные текстильные предприятия располагались в Ярославле и уездных городах. Сельские фабрики концентрировались преимущественно в селах Ярославского уезда [Александров, 2016, с. 150-151]. Большая часть текстильщиков происходила из Ярославской, Владимирской и Костромской губерний. На городских и сельских фабриках встречались дальние мигранты - рабочие из Вологодской, Нижегородской, Тверской, Московской, Тамбовской губерний. Для сельских фабрик было характерно трудоустройство жителей близлежащих волостей ${ }^{80}$.

\footnotetext{
76 Обзор Ярославской губернии за 1898-99 гг. Ярославль, 1900.

77 Российский государственный исторический архив (РГИА). Ф. 23. Оп. 30. Д. 19. Л. $28-41$.

${ }^{78}$ Государственный архив Ярославской области (ГАЯО). Ф. 642. Оп. 2. Д. 28. Л. 8, 23, $24,31$.

${ }^{79}$ ПСЗ. Собр. III. Т. Х. № 6742.

${ }^{80}$ ГАЯО. Ф. 652. Оп. 1. Д. 48; ГАЯО. Ф. 674. Оп. 1. Д. 62; ГАЯО. Ф. 676. Оп. 1. Д. 59.
} 
В городах рабочие имели возможность разместиться в фабричных казармах, снять жилье или построить собственный дом, причем женщины зачастую получали от фабрики кредиты на жилье совместно с мужем, сыновьями и другими родственниками ${ }^{81}$. Те, кто жил за городской чертой, вынуждены были регулярно возвращаться в свои села и деревни, иногда находившиеся довольно далеко от предприятия.

В итоге работа занимала основную часть в бюджете времени текстильщиков, а вкупе со временем на дорогу до фабрики и обратно оставляло небольшое количество времени для досуга, отдыха и восстановления сил. На процесс отдыха отрицательно влияло проживание рабочих в фабричных каморках, где совместно жили 3-4 семьи либо же около десятка «коллег по цеху». Повседневную жизнь рабочих могли омрачать беспокойные соседи и конфликты с ними ${ }^{82}$.

Немногое время, остававшееся после рабочего дня, а также выходные и праздничные дни рабочие могли посвятить досугу. Рассматриваемый период стал временем общей демократизации культуры, когда прежде элитарные формы досуга становились массовыми. В то же время, оказавшись в новой среде, пришлые рабочие привносили в городскую жизнь элементы крестьянской культуры. Своеобразной репликой крестьянского досуга становились фоновые досуговые практики, т. е. воспроизводство в повседневности рабочих определенных действий, мотивированных сложившимися традициями и обычаями [Ульянова, Офицерова, 2015, с. 619].

К фоновым практикам, оставшимся от крестьянского уклада жизни, можно отнести посиделки, беседы, вечеринки, а также кулачные бои, пение и танцы под гармошку, карточные игры, которые устраивались не только за воротами фабрики, но и в рабочее время, становясь причиной штрафования рабочих ${ }^{83}$. Женщины часто собирались по вечерам посидеть у корпусов ${ }^{84}$, чтобы обсудить новости и злободневные вопросы, отдохнуть от забот.

Драки были обычным вариантом досуга для мужчин, а дополняли подобные «развлечения» карты и спиртные напитки. Традиционным окружением фабрики были кабаки, трактиры, шинки, «казенки». Пьянство было широко распространено среди мужчинрабочих, но не было чуждо и женщинам. Иногда для женщин вариантом досуга становились «вечеринки» с танцами, где «кроме пошлых шуток, кокетства и грязного веселья они ничего не получали» ${ }^{85}$.

Отголоском крестьянской среды можно считать и так называемый «производственный» досуг, являвшийся репликой календарных обычаев, сопровождавших ход сельскохозяйственных работ. У ткачей сложились обычаи «засидки» и «замочки машин»- совместные празднества мужчин и женщин, приуроченные к началу зимнего или летнего сезонов работ на фабриках. В такие дни рабочие, как правило, получали от фабричной администрации угощение или деньги и продолжали празднование после работы. К началу XX в. подобные обычаи в рабочей среде практически исчезли.

К этой группе досуговых форм можно отнести «спрыски», «магарычи» и «литки», представлявшие собой угощение с алкоголем по случаю важного события. В среде городских рабочих подобные ритуалы отправлялись при поступлении или переходе на новую работу, по случаю получения первой заработной платы или ее повышения, а среди женщин по случаю свадьбы. «Спрыски» и «магарычи» устраивались в трактирах или на природе.

Отношение рабочих к такому досугу не было однозначным. В то время как одни из них активно поддерживали устоявшиеся традиции, другие относились к «спрыскам» и «магарычам» негативно, справедливо полагая, что подобные празднества наносят ущерб рабочим и их семьям. Фоновые досуговые практики продолжались в семейном быту. Фаб-

\footnotetext{
${ }^{81}$ Там же. Ф. 674. Оп. 1. Д. 4040. Л. 4-5 об., 16-16 об., 44 об.

${ }^{82}$ Там же. Оп. 1. Д. 3279. Л. 45-46.

${ }^{83}$ ГАЯО. Ф. 675. ОП. 1. Д. 168. Л. 36 об. - 37.

${ }^{84}$ Центр документации новейшей истории ГАЯО (ЦДНИ ГАЯО). Ф. 4773. Оп. 6. Д. 71. Л. 67.

${ }^{85}$ Там же. Ф. 4773. Оп. 6. Д. 223. Л. 95-96.
} 
ричным вариантом крестьянских «бабских праздников» становились так называемые «пропои помоев», устраивавшиеся два раза в год, календарно соответствуя Покрову и дню жен-мироносиц - особо почитаемым женщинами религиозным праздникам. Свое название «пропой помоев» получил по случаю сдачи коровницам помоев из фабричных казарм. К полученным деньгам добавлялись собственные средства. Празднество устраивалось в фабричных коридорах и могло продолжаться в виде шествия по улицам с песнями и танцами [Полищук, 1997, с. 117-118, 121].

Ко второй группе досуговых практик можно отнести традиционный религиознопраздничный досуг. К числу официальных праздников относились дни коронаций. Так, на текстильных фабриках широко праздновали коронацию Николая II - владельцы оплачивали подарки рабочим и организацию развлечений в честь праздника ${ }^{86}$.

Большинство государственных праздников совпадали с важными датами церковного календаря. Без религиозной жизни не мыслилось «нравственное и физическое оздоровление» рабочих. Для многих рабочих, особенно в сельской местности, церковь становилась практически единственным утешением [Сурьянинов, 1932, с. 67]. Распространенной практикой на ЯБМ и Норской мануфактуре стало празднование Пасхи и Нового года с раздачей гостинцев для рабочих и служащих. Текстильщики полюбили новогодние елки с подарками для детей и «святочные увеселения» ${ }^{87}$.

Администрация предприятий развивала отдельные формы досуга с целью отвлечения текстильщиков от «вредных» идей и пагубного времяпровождения. Так, на ЯБМ функционировало общество трезвости, была открыта воскресная школа церковного пения, «женская миссия» для работниц, церковно-приходская школа.

В XX столетии активизировалась деятельность городских и уездных комитетов попечительств о народной трезвости. Одним из направлений их деятельности стала организация народных хоров. Пение считалось хорошим средством для отвлечения населения, особенно молодежи, от пьянства. Народный хор мог участвовать в церковных службах и выступать на концертах и народных гуляниях. В репертуар хора включались народные и духовные песни. Женщины к участию в хоре допускались по усмотрению комитета в зависимости от их способностей ${ }^{88}$.

В повседневной жизни текстильщиков присутствовал культурно-образовательный досуг, доступный в формах школьного образования, посещения библиотек, публичных лекций, синематографа.

Законом 1882 г. владельцы обязывались предоставлять малолетним рабочим, не имевшим начального образования, без различия пола, возможность посещать образовательные учреждения не менее 3 часов в день и 18 часов в неделю ${ }^{89}$. Предприятия не были обязаны открывать собственные школы; дети могли посещать близлежащие учебные заведения. Одним из первых стало училище при Норской мануфактуре, открытое в 1874 г., еще до выхода соответствующего закона, в 1882 г. появилось училище при ЯБМ. С 1890-х гг. работали четырехклассная школа при Романовской мануфактуре [Жизнь во благо, 2010, с. 34] и одноклассная школа при Гаврилов-Ямской мануфактуре ${ }^{90}$. Тем не менее ряд предприятий не спешил с устройством школ. Например, едва ли не единственной возможностью получить образование для малолетних рабочих Волжской мануфактуры была школа, открывшаяся уже, вероятно, в 1905-1906 гг. и находившаяся в трех верстах от предприятия. Не случайно число детей, посещавших школу, было минимальным и составляло около 10-20 человек ${ }^{91}$.

\footnotetext{
${ }^{86}$ ГАЯО. Ф. 674. Оп. 1. Д. 2943. Л. 9, 207, 373; Ф. 675. Оп. 1. Д. 102. Л. 72.

${ }^{87}$ ГАЯО. Ф. 674. Оп. 1. Д. 4731. Л. 4 об.

${ }^{88}$ Ростовский филиал ГАЯО (РсФ ГАЯО). Ф. 69. Оп. 1. Д. 28. Л. 1-1 об., 8 об. - 9.

${ }^{89}$ ПСЗ. Собр. III. Т. II. № 931.

${ }^{90}$ ГАЯО. Ф. 642. ОП. 2. Д. 28. Л. 24 об.

${ }^{91}$ ЦДНИ ГАЯО. Ф. 4773. Оп. 6. Д. 225. Л. 49.
} 
Типичное фабричное училище представляло собой отдельное помещение или здание, часть которого могли занимать квартиры учителей. Обучение мальчиков и девочек проводилось совместно, курс училища составлял 3-4 года; учебные материалы выдавались за счет предприятий. Фабрики практиковали награждение выдающихся выпускников книгами и похвальными листами [Ярославская Большая мануфактура, 1900, с. 60]. Программа обучения включала арифметику, письмо, чтение, закон Божий, пение и т. д. На ЯБМ велось раздельное обучение мальчиков и девочек по гимнастике и рукоделию.

«Разумным» способом проведения свободного времени стала фабричная библиотека, бесплатно выдававшая книги рабочим. «Отделами» фабричных библиотек являлись русская словесность, религиозно-нравственные и исторические произведения. Можно отметить библиотеки-читальни при ЯБМ (1895 г.) и Норской мануфактуре (1892 г.). Последняя насчитывала к началу XX столетия более полутора тысяч изданий, и на каждого абонента приходилось в год по 32 книги [Норская мануфактура, 1900, с. 14].

Популярной формой досуга текстильщиков стали лекции с демонстрацией туманных картин, проводившиеся крупными предприятиями - ЯБМ, Норской и Романовской мануфактурами. В Ростове устройством публичных лекций занимался местный комитет попечительства о народной трезвости ${ }^{92}$. Лекции устраивались по воскресным и праздничным дням, собирая значительное количество слушателей в фабричных или арендованных помещениях. «Телеустройства» или волшебные фонари приобретались организаторами либо брались в аренду. Как правило, чтения имели несколько отделений: религиознонравственное, историческое, научное и литературное. Плата за посещение чтений не взималась. Чтения привлекали целые семьи текстильщиков, становясь альтернативой досугу нездоровому.

Фабричный театр также разнообразил досуг рабочих. Толчок к развитию театрального дела давали фабричные школы. Например, в начале XX столетия при школе Норской мануфактуры работала актерская труппа, в состав которой входили рабочие [Виноградов и др., 1976, с. 22]. Драматический кружок существовал при школе Романовской мануфактуры [Жизнь во благо, 2010, с. 42]. С 1894 г. на ЯБМ спектакли ставились в здании фабричного училища, располагавшего залом на полторы тысячи мест. Часто устраивались детские спектакли.

Спектакли для рабочих обычно были платными, но стоимость их (к 1905 г. - 4 коп.) оставалась доступной. Часть расходов на организацию постановок предприятие и общество служащих брали на себя. Собранные средства шли на изготовление костюмов и декораций. Ставились также благотворительные спектакли, так, в 1904 г. были организованы постановки и публичные лекции в пользу раненых в русско-японской войне ${ }^{93}$. На сцене фабричного училища ЯБМ играли артисты городского театра и гастролирующие труппы. Администрация ЯБМ организовывала сеансы синематографа для рабочих и служащих ${ }^{94}$.

Важной частью жизни текстильщиков становилась общественно-политическая деятельность. Согласно воспоминаниям рабочих, они занимались агитацией, распространением нелегальной литературы и листовок, участвовали в собраниях. Некоторые женщины, в первую очередь, выросшие в среде «идейных» текстильщиков, также вовлекались в общественную работу 95 .

Тем не менее по своему содержанию и объему досуг женщины-работницы представляется более скудным, нежели досуг рабочего-мужчины. Текстильщицы традиционно продолжали посвящать себя заботам о доме, хозяйстве, муже, детях и родственниках.

\footnotetext{
92 РсФ ГАЯО. Ф. 69. Оп. 1. Д. 27. Л. 2-41.

${ }^{93}$ ГАЯО. Ф. 674. ОП. 1. Д. 4731. Л. 1.

94 Там же. Л. 8 об.

${ }^{95}$ ЦДНИ ГАЯО. Ф. 4773. Оп. 6. Д. 72. Л. 43 об., 68-70.
} 
Многосемейность и сложные бытовые условия сокращали объем и без того непродолжительного свободного времени.

Больше досуговых возможностей, конечно, имели дети и подростки. Однако появление в семье маленьких детей или отсутствие средств приводили к тому, что уже с самого юного возраста девочки были вынуждены искать работу. Работа нянькой, швеей или работа на фабрике, а также помощь родителям в хозяйстве фактически лишала их детства и свободного времени. Многие работницы указывали на необходимость работать и жить в непростых условиях, на отсутствие возможности учиться или продолжать обучение ${ }^{96}$.

Досуг одиноких работниц несколько отличался от досуга семейных женщин. Такая работница могла уделять больше времени досугу ввиду отсутствия у нее «семейных обстоятельств». К сожалению, часть одиноких работниц посвящала свое время девиантному досугу, включавшему пьянство и «свободные» отношения с коллегами по цеху 97.

Появление семьи также не способствовало прибавлению свободного времени у текстильщиц. Хозяйственные заботы, уход за детьми, а зачастую еще и за пьющим мужем фактически заставляли многих работниц брать на себя главенствующую роль в семье. В связи с этим представляется очевидным преобладание в повседневной жизни текстильщиц элементов фонового и религиозно-праздничного досуга.

Развитие текстильной промышленности оказывало значительное влияние на обыденную жизнь населения, меняя не только круг повседневных задач и обязанностей, но и идентичность, и ментальность рабочих. Несмотря на позитивные изменения в соотношении досуга и труда в бюджете времени фабричных рабочих, в рассматриваемый период повседневная жизнь ярославских текстильщиц по-прежнему отличалась высокой продолжительностью рабочего дня и монотонностью труда. Работа на фабрике переходила в работу по хозяйству, а многочисленные семейно-бытовые трудности снижали качество жизни женщин, фактически полностью поглощая имевшееся в их распоряжении свободное время либо максимально ограничивая его в будни и выходные дни. Несмотря на это, в последние десятилетия XIX - начале XX в. отчетливо наметилась тенденция к увеличению доли досуга в бюджете времени работниц ярославских текстильных фабрик, а также расширению круга досуговых форм, позволивших работницам хотя бы отчасти изменить собственную повседневную жизнь в лучшую сторону.

\section{Список литературы}

1. Александров Н.М. 2016. Крестьянский отход и текстильная промышленность пореформенной России (по материалам Верхнего Поволжья). В кн.: Историки: Формирование исторической школы в Ярославском государственном университете. Сборник воспоминаний и материалов. Иваново, ИП А.А. Пряслов: 148-156.

2. Беликов Б.Д. 1914. Женщина в промышленной инспекции Запада: к вопросу о введении женской фабричной инспекции в России. Тверь, Типо-Литография М.В. Блинова, преемн. Н.М. Родионова, 63.

3. Бородкин Л.И., Валетов Т.Я., Смирнова Ю.Б., Шильникова И.В. 2010. «Не рублем единым»: трудовые стимулы рабочих-текстильщиков дореволюционной России. Москва, РОССПЭН, 534.

4. Веременко В.А. 2014. Подготовка дворянок к хозяйственной деятельности в семье в России второй половины XIX - начала XX вв. Вестник Ленинградского государственного университета им. А.С. Пушкина, 4 (4): 62-75.

5. Виноградов М.В., Землянский А.Ф., Карасев С.М. 1976. «Красный Перевал»: Очерки истории фабрики. Ярославль, Верхне-Волжское книжное издательство, 294.

6. Жизнь во благо: памяти Е.Е. Классена (1842-1910): сборник статей и материалов. Под ред. Н.В. Обнорской. Ярославль, Конверсия, 2010, 47.

\footnotetext{
96 Там же. Д. 71. Л. 53.

${ }^{97}$ ГАЯО. Ф. 674. Оп. 1. Д. 3279. Л. 55 об.
} 
7. Залунаева Е.А. 2005. Повседневная жизнь рабочих Ярославля во второй половине XIX начале XX вв. Автореф. дис. ... канд. ист. наук. Ярославль, 26.

8. Кирьянов Ю.И. 1979. Жизненный уровень рабочих России (конец XIX - начало XX в.). Москва, Наука, 287.

9. Марасанова В.М., Албегова И.Ф., Шаматонова Г.Л. 2013. Женщины и профессиональнополитические организации в Ярославской губернии на рубеже XIX-XX вв. Женщина в российском обществе, 67 (2): 60-69.

10. Полищук Н.С. 1997. Обычаи и нравы рабочих России (конец XIX - начало XX вв.). В кн.: Рабочие и интеллигенция России в эпоху реформ и революций. 1861 - февраль 1917 г. СанктПетербург, Издательство “Русско-Балтийский Информационный центр «БЛИЦ»”: 114-130.

11. Посвятенко Ю.В. 2011. Особенности повседневной жизни рабочих-текстильщиков Верхнего Поволжья во второй половине XIX - начале XX вв. Москва, Контент-пресс, 241.

12. Пушкарева Н.Л., Мицюк Н.А. 2016. Модернизация репродуктивного поведения образованных россиянок второй половины XIX - начала XX в. Женщина в российском обществе, 80 (3): 73-89.

13. Сурьянинов С. 1932. Фабрика «Красный перевал» (б. Норская мануфактура). Москва, Государственное экономическое издательство, 76.

14. Ульянова С.Б., Офицерова Н.В. 2015. Фоновые досуговые практики советских городских рабочих в 1920-е гг. В кн.: Историческая урбанистика: прошлое и настоящее города. Курган, ООО «Курганский Дом печати»: 618-629.

15. Baron A. 1982. Women and the making of the American working class. A study of the proletarization of printers. Review of Radical Political Economics, 14 (3): 23-42.

16. Benenson H. 2019. The «family wage» and the working women's consciousness in Britain, 1880-1914. Politics and Society, 1: 71-108.

17. Boyer K. 2004. «Miss Remington» goes to work: gender, space, and technology at the dawn of the Information Age. The Professional Geographer, 56 (2): 201-212.

18. Hunter J. 1993. Japanese women at work. History Today, 43 (5): 49-55.

19. James K.J. 2006. Handycraft, Mass Manufacture and Rural Female Labour: Indusrtial Work in North-West Ireland, 1890-1914. Rural History, 17 (1): 47-63.

20. Purdue O. 2017. Surviving the industrial city: the female poor and the workhouse in late nineteenth-century Belfast. Urban History, 44 (1): 69-90.

\section{References}

1. Aleksandrov N.M. 2016. Krest'yanskiy otkhod i tekstil'naya promyshlennost' poreformennoy Rossii (po materialam Verkhnego Povolzh'ya) [Peasant Seasonal Works and Textile Industry in PostReform Russia (the Upper-Volga Region)]. In: Istoriki: Formirovanie istoricheskoi shkoly v Yaroslavskom gosudarstvennom universitete. Sbornik vospominanii i materialov. Ivanovo, IP A.A. Pryaslov: 148-156 (in Russian).

2. Belikov B.D. 1914. Zhenshchina v promyshlennoy inspektsii Zapada: $\mathrm{k}$ voprosu o vvedenii zhenskoy fabrichnoy inspektsii v Rossii [Woman and the Western Industrial Inspection: on the Issue of Establishment of the Female Factory Inspection in Russia]. Tver, Tipo-Litografiya M.V. Blinova, preemn. N.M. Rodionova, 63 (in Russian).

3. Borodkin L.I., Valetov T.Ya., Smirnova Yu.B., Shil'nikova I.V. 2010. «Ne rublem edinym»: trudovye stimuly rabochikh-tekstil'shchikov dorevolyutsionnoy Rossii [«Not by a Ruble Alone»: Labor Motivation for Textile Workers in Pre-revolutionary Russia]. Moscow, ROSSPEN, 534 (in Russian).

4. Veremenko V.A. 2014. Podgotovka dvoryanok k khozyaystvennoy deyatel'nosti v sem'e v Rossii vtoroy poloviny XIX - nachala XX vv. [Preparation of the noble women to economic activity in the family in Russia in the second half of XIX - early XX centuries]. Vestnik Leningradskogo gosudarstvennogo universiteta im. A. S. Pushkina, 4 (4): 62-75 (in Russian).

5. Vinogradov M.V., Zemlyanskiy A.F., Karasev S.M. 1976. «Krasnyy Pereval»: Ocherki istorii fabriki [«Krasny Pereval»: Outline of the Factory's History]. Yaroslavl, Verkhne-Volzhskoe knizhnoe izdatel'stvo, 294 (in Russian).

6. Zhizn' vo blago: pamyati E.E. Klassena (1842-1910): sbornik statey i materialov [Life for the good: in memory of E.E. Classen (1842-1910)]. Pod red. N.V. Obnorskoy. Yaroslavl, Konversiya, 2010, 47 (in Russian). 
7. Zalunaeva E.A. 2005. Povsednevnaya zhizn' rabochikh Yaroslavlya vo vtoroy polovine XIX nachale XX vv. [Everyday Life of the Yaroslavl Workers in the Second Half of the XIX - the Beginning of the XX cc.]. Abstract. dis. ... cand. hist. sciences. Yaroslavl, 26 (in Russian).

8. Kir'yanov Yu.I. 1979. Zhiznennyy uroven' rabochikh Rossii (konets XIX - nachalo XX v.). [Living Standard of Russian Workers]. Moscow, Nauka, 287 (in Russian).

9. Marasanova V.M., Albegova I.F., Shamatonova G.L. 2013. Zhenshchiny i professional'nopoliticheskie organizatsii v Yaroslavskoy gubernii na rubezhe XIX-XX vv. [Women and professional and political organizations in the Yaroslavl province at the boundary of the XIX-XX cc.]. Zhenshchina v rossiyskom obshchestve, 67 (2): 60-69 (in Russian).

10. Polishchuk N.S. 1997. Obychai i nravy rabochikh Rossii (konets XIX - nachalo XX vv.). [Customs and Folkways of the Russian Workers (end of XIX - beginning of XX cc.)]. In: Rabochie i intelligentsiya Rossii v epokhu reform i revolyutsiy. 1861 - fevral' 1917 g. St. Petersburg: Izdatel'stvo "Russko-Baltiiskii Informatsionnyi tsentr «BLITS»": 114-130 (in Russian).

11. Posvyatenko Yu.V. 2011. Osobennosti povsednevnoy zhizni rabochikh-tekstil'shchikov Verkhnego Povolzh'ya vo vtoroy polovine XIX - nachale XX vv. [Pecularities of the Textile Workers' Everyday Life in the Upper Volga Region]. Moscow, Kontent-press, 241 (in Russian).

12. Pushkareva N.L., Mitsyuk N.A. 2016. Modernizatsiya reproduktivnogo povedeniya obrazovannykh rossiyanok vtoroy poloviny XIX - nachala XX v. [Modernization of reproductive behavior of noblewomen in the second half of XIX - the beginning of the XX c.]. Zhenshchina $\mathrm{v}$ rossiyskom obshchestve, 80 (3): 73-89 (in Russian).

13. Sur'yaninov S. 1932. Fabrika «Krasnyy pereval» (b. Norskaya manufaktura) [Krasny Pereval Factory (Former Norskaya Manufacture)]. Moscow, Gosudarstvennoe ekonomicheskoe izdatel'stvo, 76 (in Russian).

14. Ul'yanova S.B., Ofitserova N.V. 2015. Fonovye dosugovye praktiki sovetskikh gorodskikh rabochikh v 1920-e gg. [The background free time practice of Soviet urban workers in the 1920s]. In: Istoricheskaya urbanistika: proshloe i nastoyashchee goroda. Kurgan, OOO «Kurganskiy Dom pechati»: 618-629 (in Russian).

15. Baron A. 1982. Women and the making of the American working class. A study of the proletarization of printers. Review of Radical Political Economics, 14 (3): 23-42.

16. Benenson H. 2019. The «family wage» and the working women's consciousness in Britain, 1880-1914. Politics and Society, 1: 71-108.

17. Boyer K. 2004. «Miss Remington» goes to work: gender, space, and technology at the dawn of the Information Age. The Professional Geographer, 56 (2): 201-212.

18. Hunter J. 1993. Japanese women at work. History Today, 43 (5): 49-55.

19. James K.J. 2006. Handycraft, Mass Manufacture and Rural Female Labour: Indusrtial Work in North-West Ireland, 1890-1914. Rural History, 17 (1): 47-63.

20. Purdue O. 2017. Surviving the industrial city: the female poor and the workhouse in late nineteenth-century Belfast. Urban History, 44 (1): 69-90.

\section{ИНФОРМАЦИЯ ОБ АВТОРАХ}

Марасанова Виктория Михайловна, доктор исторических наук, профессор, заведующая кафедрой рекламы и связей с общественностью Ярославского государственного университета им. П.Г. Демидова, г. Ярославль, Россия

Кривошеева Юлия Александровна, старший преподаватель кафедры рекламы и связей с общественностью Ярославского государственного университета им. П.Г. Демидова, г. Ярославль, Россия

\section{INFORMATION ABOUT THE AUTHORS}

Victoria M. Marasanova, Doctor of Sciences (History), Professor, Head of the Department of Advertisement and Public Relations, P.G. Demidov Yaroslavl State University, Yaroslavl, Russia

Julija A. Krivosheeva, Senior Lecturer of the Department of Advertisement and Public Relations, P.G. Demidov Yaroslavl State University, Yaroslavl, Russia 